\title{
EET Intervention on HO-1 Prevent Obesity Derived Cardiovascular Diseases
}

Lu Liu, Xin Huang, Jinliao Gao, Yusong Guo, Yanqi Di, Shasha Sun and Jian Cao*

Department of Cardiology, Nanlou Division, Chinese PLA General Hospital, National Clinical Research Center for Geriatric Diseases, Beijing 100853, China

\begin{abstract}
The increase in the prevalence of obesity represents a worldwide phenomenon and is correlated with several metabolic and cardiovascular diseases, and cardiovascular disease remains the leading cause of death worldwide. And epoxyeicosatrienoic acid (EET), correlated with heme oxygenase $(\mathrm{HO})$, with emerge to be a promising strategy for pharmacological mediation. Moreover, inhibit soluble epoxide hydroxylase (sEH), the enzyme converts EET to less potent metabolite, could upregulate EET concentration, which could upregulate $\mathrm{HO}-1$, working together to reduce inflammation and increase vasodilation, in order to improve endothelial and cardiac function. The EET-HO pathway has been indicated as a most potent target for reversing oxidative stress and pre-adipocyte differentiation, so as to moderate oxidative capacity in mitochondrial dysfunction. While EET agonists and sEH inhibitors are becoming one of the potential therapies, and some of them are already in clinical trials. This review serves to summarize the ability of EET and HO pathway in attenuating the clinical impairments of obesity and associated cardiovascular diseases.
\end{abstract}

Keywords: Obesity, PGC-1a; Epoxyeicosatrienoic acid; Cardiotrophin; Adiponectin; Hyperthermia

\section{Introduction}

\section{Differential phenotype between white fat and brite fat}

Adipose tissue is not only a type of connective tissue but an endocrine organ with two very important roles in the mammalian body: energy homeostasis and reproduction $[1,2]$. Apart from these, fat also prevent delicate organs and from mechanical stress. What should be noticed is that it is not the number of adipocytes that change in obesity (namely hyperplasia) but change in size (hypertrophy of adipocytes) [3].

Traditionally, fat can be metabolized into two difference types: white and brown fat. White fat could be found in models of obesity and metabolic syndrome, which make up the bulk of fatty tissue in the animals [4], and brown fat could be seen in the supraclavicular and spinal region of infants and rodents, and human adults also have brown fat specific depots [5]. White adipocytes are associated with very large lipid droplets with an energy storing effect [4], while brown fat is associated with smaller lipid droplets can dissipate stored chemical energy as an energy releasing phenotype [6]. Brown fat can be activated by either cold exposure or $\beta$ adrenergic signalling and is linked to mitochondrial uncoupling protein (UCP1) to uncouple ATP from the electron transport chain, and lead energy consumption to combat hypothermia, obesity, and diabetes [7].

Brown fat comes from a Myf5+/Pax7+ cellular lineage, which is different from white fat, and muscle tissue also stems from this cellular lineage [8]. Although the cellular lineages are different, the core elements of the adipogenic cascade are shared by all types of fat. PPAR $\gamma$ is the main manager of fat cell formation, and Zfp423 is a significant transcriptional factor of adipocyte lineage with bZIP, CEBP $\alpha$ and $\beta$ to be transcriptional cofactors, and this cascade works for both white and brown fat $[9,10]$. Moreover, CEBPa is locked in a differentiation loop with PPAR $\gamma$, and one increase the other does as well [9]. Ebf2 is an important protein that recruits PPAR $\gamma$ in brown fat, and much of the specialized brown fat function is controlled by transcriptional cofactors such as Ebf2 [11]. Although they don't bind DNA directly, they both control which targets will be bound and which will be activated [12]. The SNS plays a critical part in fat development as well, which distributes signals to both white adipose and brown adipose [13]. These different signals indicated that the effect of cold exposure is very different than food deprivation.
Obesity has a whole body effect and can lead to diabetes, hypertension, and all known inflammatory markers are associated in obesity [14-16]. Adipocytes are a major source of TNFa and relate with recruit macrophages [17]. There are two types of macrophages: the classically activated M1 macrophages (release IL-6, are proinflammatory) and the alternatively activated M2 macrophages (release IL 10, anti-inflammatory, involved in wound healing) [18]. The ratio of M1/M2 shifted to a pro-inflammatory state in obesity body [19], and these inflammations can cut off the adipocytes oxygen, resulting in an activation of HIF1a (oxygen sensing transcription factor) which lead to metabolic dysfunction [20]. Adipocytes are extremely beneficial and vital for homeostatic balance in normal body, but these indicated over nutrition leads to obesity, and switch the normal balance towards inflammation.

Beside from white and brown fat, there is a third category of fat has been elucidated like "beige" or "brite" fat, which is a unique type of fat distinct from the other two types of fat [21]. Brite adipocytes are not from the same cell lineage like brown fat, they are from either trans differentiation of mature white adipose or unique precursor in white cells [22].

Beige cells could express abundant UCP1 and a broad gene program that is unique, and they can switch between an energy storing and energy releasing phenotype depends on environmental cues and conditions [23]. These brite cells have very low basal UCP1 expression like white adipose when unstimulated, while they will have turned to have a thermogenic profile similar to brown fat once stimulated [24]. Compared to classical brown fat, these cells have a coinciding but distinct gene pattern. Brite cell (which with low basal UCP1 expression and low uncoupled respiration like white fat) can be unstimulated by

${ }^{*}$ Corresponding author: Jian Cao, Department of Cardiology, Nanlou Division, Chinese PLA General Hospital, National Clinical Research Center for Geriatric Diseases, Beijing 100853, China, E-mail: calvin301@163.com

Received May 03, 2018; Accepted May 22, 2018; Published May 28, 2018

Citation: Liu L, Huang X, Gao J, Guo Y, Di Y, et al. (2018) EET Intervention on HO-1 Prevent Obesity Derived Cardiovascular Diseases. J Biomol Res Ther 7: 163. doi:10.4172/2167-7956.1000163

Copyright: @ 2018 Liu L, et al. This is an open-access article distributed under the terms of the Creative Commons Attribution License, which permits unrestricted use, distribution, and reproduction in any medium, provided the original author and source are credited. 
the stimulation with $\beta$ adrenergic agonists, with the elevated levels of UCP1, while uncouple respiration to those of brown fat or above [25]. Brite cells are bifunctional; they can be fit for energy storage in absence of thermogenic stimuli, and can turn back to an energy releasing mechanism when necessary [26]. Moreover, brite fat contains a higher proportion of $\mathrm{M} 2$ macrophages, demonstrating a lean towards a healthier metabolic phenotype [27].

There are elements could induce browning of white adipocytes such as thyroid hormone T3, irisin, and cardiotrophin [28-30]. Irisin is a hormone released by the muscle during exercise, and the irisin response may be beige specific [29]. Brown and brite adipose tissues have a very different genetic profile, but UCP1 is shared by both types even the amount is variable, because brite tissue can change UCP1 expression it needed [31].

PRDM16 is a significant transcriptional factor for brown adipocytes [32], and it was shown to be a determining factor in the muscle/brown adipose Myf5+ lineage [33]. The cells become muscle when PRDM16 is knockout and become brown adipose when it overexpressed [31].

Moreover, all types of tissue can release adiponectin, leptin, and resistin [34]. Leptin endorses inflammation [35], adiponectin is approvingly adipose specific, and resistin is highly white adipose specific which could link obesity to insulin resistance [36]. Brown adipose may have the same adipokines as white adipose with a lower concentration, and it also has its own set of "batokines" such as IL-6 [37], which indicated by the study that ablation of brown adipose has a much higher influence on systemic metabolism than simply UCP1 deletion.

There are very noticeable differences between white adipose and brown adipose, and brite adipose as a completely separate category on its own with a different set of gene, which the ability to switch between an energy releasing and storing phenotype, may hold a potential key to the obesity problem currently facing the world.

\section{Obesity and Cardiovascular Diseases}

The increase in the prevalence of obesity represents a worldwide phenomenon and is correlated with several metabolic and cardiovascular diseases. Based on several researches, obesity was emphasized to be the central role in the development of metabolic syndrome, which is characterized with obesity, hypertension, hyperglycemia and hyperlipidemia, as well as to increase the susceptibility for cardiovascular disease and diabetes [38]. Obesity, which contain more and larger adipocyte, is showed with increases chronic low-grade inflammation, and is the key point in the proliferation of interrelated hyperglycemia and endothelial dysfunction due to elevated lowdensity-lipoproteins (LDL) and oxidative stress $[39,40]$. High level of cardiac oxidative stress is the early stage of heart dysfunction due to obesity, and it was always after insulin resistance with altered fatty acid and glucose metabolism [41]. The alternations of electron transport chain proteins related to mitochondrial ATP production [42], and the etiology of obesity is linked to the imbalance in energy consumption and expenditure [43], leading to a decrease of the efficiency of cardiac work. Most of obese patients without hypertension will have early segmental systolic and diastolic dysfunctions even the global function is normal [44], and abnormal left ventricular energy metabolism has been detected. In obesity patients which developed into heart failure, left ventricular (LV) was observed increasing in both chamber size and wall thickness (LV hypertrophy), which leads to diastolic dysfunction and cardiac ischemia in obesity, and pericardial fat is significantly associated with LV diastolic dysfunction [45]. Therefore, obesity is a risk factor for cardiovascular morbidity and mortality, as it is associated with alterations in cardiac structure [46], and left ventricular changes [47], resulting into left ventricular hypertrophy.

Heart and adipose tissue have a connection in regulation of energy metabolism [48]. Leptin was identified as an adipocyte-secreted hormone, which functions as a peripheral signal to communicate the organism's energy reserve [49]. While the heart is also included in energy network through the regulation of cardiac hormones natriuretic peptides identified as blood pressure control [50]. The natriuretic peptides stimulate triglyceride lipolysis in adipoctyes, promote uncoupling of mitochondrial respiration and thermogenesis in brown adipocytes via p38 MAPK [51].

Moreover, we know that BMI and fat mass are main independent causes of plasma nephroblastoma overexpressed (NOV) concentration, and NOV is a circulating protein that is also detected in diverse human tissues including the adrenal cortex, central nervous systems, kidney, musculoskeletal, heart and blood vessels [52], indicating the importance of NOV during cardiac development and vascular homeostasis [53]. NOV belongs to CCN family, which composed of six members, NOV is CCN3 \{PMC5055498\}. Studies found out there is a significant gender effect on plasma NOV concentration with women displaying a higher level of circulating NOV compared to men [52]. And it indicated that the plasma lipid profile was connected to plasma NOV after adjustment for gender. It is notable that plasma NOV is also related to physical activity, which also control plasma triglycerides [54]. Moreover, Wnt1 inducible signalling pathway protein 1 (WISP$1 / \mathrm{CCN} 4)$ is a novel adipokine, which is upregulated in obesity, and induces a pro-inflammatory response in macrophages in vitro [55]. Wnts are signaling proteins that could control diverse biological processes, such as cell proliferation and angiogenesis [56]. While Wnt1 is secreted from primary human endothelial cells, and Wnt1/b-catenin signalling stimulates angiogenesis [57]. Angiogenesis is vital for the restoration of the blood supply to the infarct area, and it has influence on the revascularization of the perinecrotic area leading to the recovery of viable myocardium [58]. While noncanonical Wnt signalling like wnt5a, upregulated in human visceral fat compared with subcutaneous fat in obese individuals, contributes to obesity-associated metabolic dysfunction by increasing adipose tissue inflammation $[59,60]$. And as NOV, wnt and inflammation are linked, it is important to keep the balance so as to treat obesity and associated diseases.

Now these days, obesity becomes one of the new health problems especially when it occurs in cardiovascular diseases and browning the cardiac and peri-vascular adipose tissue is important in modulate cardiovascular risk [61] (Figure 1).

\section{Mitochondrial Function and ROS in Obesity Induced Cardiovascular Diseases}

Mitochondria in obese indexes showed decreased bioenergetics capacities and fatty acid oxidation, leading to lipid accumulation to muscular tissue [62]. And mice fed with high fat diet showed respiratory capabilities impaired by mitochondrial dysfunction [63], and the mitochondrial deficiency caused by insufficient antioxidant defences and overproduction of ROS become a potent source for energy-dependent disturbances such as inflammation [64]. ROS can be generated from many sources, such as nitric oxide (NO) synthases, cytochrome P450 enzymes and nicotinamide adenine dinucleotide phosphate (NADPH) oxidases [65]. ROS act as a signalling molecule in regulation of cellular events such as cell growth. However, 


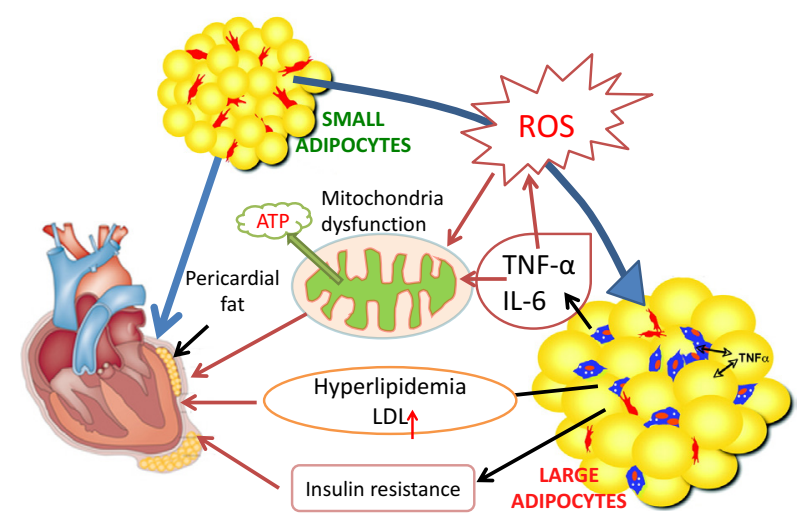

Figure 1: Obesity and associated metabolic diseases.

overexpression of ROS is associated with cell dysfunction and death [66], and mitochondria have been suggested to be the major intracellular site of ROS production [67]. While oxidative stress in mitochondrial dysfunction lead to downregulation of NO synthesis via upregulation of angiotensin II and 20-HETE, induces hypertension and vasoconstriction, oxidizes both low and high-density-lipoproteins, facilitates adipocyte differentiation and promotes inflammatory signalling [68-70].

Mitochondria are the primary source of intracellular energy, efficient mitochondrial function is critical [71]. The function of mitochondrial network depends on quality control, referring to fusion and fission. Mitofusin 1 and 2 (Mfn1 and 2) facilitate the mitochondrial fusion process [72], while COX-1 is related to the mitochondrial oxidative phosphorylation (OXPHOS) [73]. Brown adipose tissue is specialized to expend energy as heat by uncoupling respiration with its unique mitochondrial membrane embedded protein uncoupling protein-1 (UCP1), a process known as nonshivering thermogenesis [26], which increases heat production through an uncoupling oxidative metabolism from ATP production [74].

Proper mitochondrial function is necessary in tissues and organs in high energy demand, and multiple studies have indicated that mitochondria play a vital role in energy production, extending furthermore into thermogenesis, fatty acid oxidation, heme biosynthesis, as well as cell signalling $[75,76]$. The multifactorial nature of mitochondrial biology parallels the numerous pathophysiological fluctuations underlying metabolic detriments thought to develop as a result of mitochondrial dysfunction and disturbances in energy homeostasis [75,77].

Uncoupling of the electron transport chain in dysfunctional mitochondria results in overproduction of ROS, downregulation of ATP, extensive cell damage, and apoptosis of cardiomyocytes $[78,79]$. And in turn, the unbalance of nutrient and oxygen supply and undergo metabolic adaptation in cardiovascular diseases, which mitochondria is extremely sensitive to, leading to a progressive reduce of the mitochondrial function and loss of mitochondria structural integrity, associated with abnormalities in the respiratory chain and ATP synthesis and increase oxidative stress [80]. And the oxidative stress will make adipocyte into white fat, and deregulation of this process with failing heart and damaged mitochondria will make the situation more adverse.

Another contributor to adipose dysfunction is the NAD+/ SIRT pathway [81,82]. Several studies represented the negative correspondence of SIRT expression with adiposity, insulin resistance, as well as inflammation and impaired mitochondrial quality control $[83,84]$. The downregulation of SIRT1 has been exhibited to subsequently decrease AMP-activated protein kinase (AMPK) [85], which acts as a vital role in the regulation of energy balance, could induce catabolic cellular states and promote fatty acid oxidation by modulating mitochondrial activity [86,87]. Whereas inhibition of AMPK could decrease adiponectin level while promote insulin resistance, increase abdominal obesity, upregulate LDL cholesterol, and reduce mitochondrial biogenesis [88-90], and the dyslipidemia subsequent from mitochondrial dysfunction may further deteriorate insulin resistance via altered fatty acid metabolism [91], which deteriorate obesity and associated metabolic diseases (Figure 1).

\section{Epoxyeicosatrienoic Acids (EETs) Synthesis}

Epoxyeicosatrienoic acids (EETs) are lipid mediators, which derived from arachidonic acid (AA) by CYP 450 pathway [92]. It could regulate blood pressure, inflammatory and glucose homeostasis [93], while it could be further hydrolyzed to lass active diols by the enzyme soluble epoxide hydrolase (sEH) [94].

Arachidonic acid (AA) is the most biologically relevant omega-6 polyunsaturated fatty acid (PUFA) and is present in phospholipids of the cell membrane, and it is able to constitute the backbone of a triglyceride, and the release of AA from phospholipids is achieved through the activity of the enzyme phospholipase A2 (PLA2) [95]. Eciosanoids are fatty acid metabolites derived from PUFAs. AA is subject to three metabolic pathyways: cyclooxygenase (COX) is responsible for the prostaglandins, and lipoxygenase (LOX) results in the leukotrienes, while cytochrome P450 (CYP) constitute a major metabolic pathway $[96,97]$. AA is oxidize by the CYP enzyme into two different reactions: olefin epoxidation, which generates four epoxiyeicosatrienoic acids (5, 6-EET, 8, 9-EET, 11, 12-EET and 14, 15-EET) and hydroxylation (20-HETE) [98,99]. In human, CYP2C9, CYP2C19 and CYP2J2 are the major enzymes that convert AA to EETs, while 11,12- and 14,15-EETs are the main products [100,101].

EETs play a vital role in regulating physiological and pathophysiological processes, which formed endogenously in various tissues and exert potent biological effect on cellular functions [102]. However, via the activity of $s E H, E E T$ is converted into dihydroxyeicosatrienoic acid (DHET), which has a decreased activity [103]. $\mathrm{sEH}$ is present in many mammalian tissues, including the myocardium, adipose, liver, kidney and blood vessels [93]. The C-terminal domain of soluble epoxide hydrolase (sEH) enzyme is responsible for the hydrolysis of EETs, whereas the N-terminal domain has lipid phosphatase activity [71]. Inhibition of she results in EET accumulation and retention in tissues [104], and do benefit to cardiovascular diseases [103] (Figure 2).

\section{Heme Oxygenase and its Derived Productions}

Studies have indicated that EET could upregulate heme oxygenase1 (HO-1) activity and expression [97,105], which offers protection of vascular and regulation of adipocyte formation [106]. The mechanism by which EET increases HO-1 could be related to the increase in $\mathrm{BACH} 1$ which is a suppressor of HMOX1, regulated by EET through glucocorticoid and AP-1 binding sites [107], which subsequently increase $\mathrm{HO}$ activity.

$\mathrm{HO}$, an essential stress response protein, has two isoforms: HO1(inducible) and HO-2(constitutive) [108], can be metabolized into bilirubin, carbon monoxide and iron [109], so as to decrease the injury 
from heme and ROS [110,111]. HO-1 can be induced by an extremely wide diversity of drugs and chemical agents, such as aspirin, statins, eicosanoids like EET and free metals [108].

Carbon monoxide (CO) has been studied in both cell and human physiology, and has many benefit including increasing mitochondrial function in mesenchymal stem cells $[112,113]$, improving sepsis in stem cells [114], and modulating of inflammation [115,116]. Moreover, $\mathrm{CO}$ can act as a gasotransmitter, a potent regulator of vascular homeostasis, decreases vasoconstriction and stimulates vasodilation, and instantaneously increases insulin secretion [117].

The HO-1 derived bilirubin can prevent oxidant-mediated cellular damage and attenuate oxidant stress [118], and have the potential benefit to protect obesity and metabolic syndrome through increasing insulin sensitivity and suppressing chronic inflammation [119]. Moreover, studies indicated that bilirubin can inhibit the oxidation of low denisity lipoproteins (LDL) [120], and is associated with a decreased risk for coronary artery disease in humans [121,122].

The degradation of heme results in the dispersion of iron, which is known to dispose the production of ROS [123]. The upregulation of HO-1 correspondences a concurrent increase in anti-oxidant ferritin [124], the toxic effects of iron-mediated oxidative damage couple a parallel rise in ferritin concentrations as a means for anti-oxidant and anti-inflammatory response $[125,126]$ (Figure 3 ).

\section{Impact of EET and HO-1on Adipogenesis and Obesity}

A large evidence suggested that adipocyte oxidative stress is fundamental reason in the pathogenesis of obesity, and it can cause dysregulation of inflammation-related adipocytokines, leading to cardiovascular complications [115]. Adipocytes belong to mesodermal origin and bone marrow stromal cells, and serve as a reservoir for the preadipocytes recruitment and generation [127,128]. It is well known that during adipogenesis, upregulation of ROS will differentiate adipocytes produce much more ROS than preadipocytes [129]. Morphologically, this adipocyte differentiated under oxidizing conditions are investigated by Oil Red $\mathrm{O}$ detection of lipid accumulation [130].

The effect of EETs on adipogenesis and the associated signaling cascades involved in adipogenesis including HO-1, adiponectin, AMPK, and pAkT have been studied in recent years [131]. And it was known that the $\mathrm{HO}$ system act as an cellular antioxidant defense system in obesity

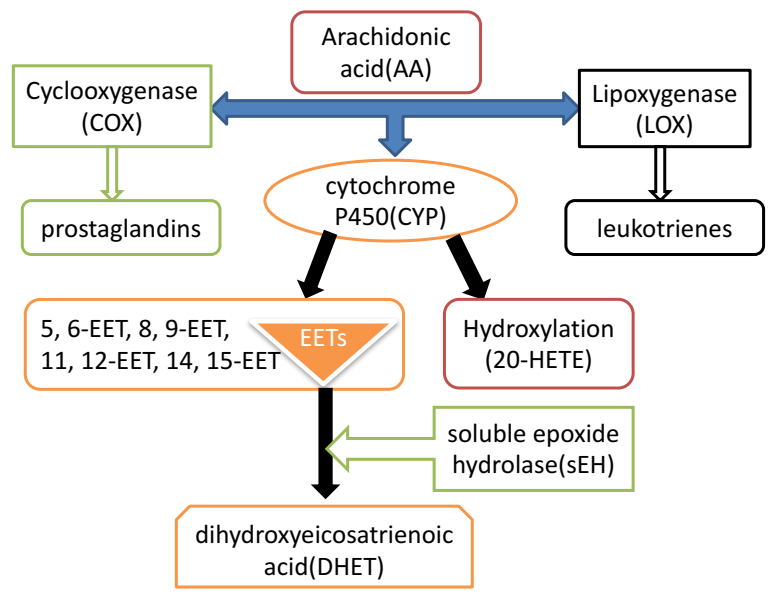

Figure 2: Heme oxygenase and its derived productions. and diabetes [109], whereas epoxides have anti-inflammatory [92] and antihypertensive effects [132] and EET suppression could contribute to hyperlidemic states. It is indicated that human MSC-derived adipocytes could express CYP 2J2 and produce EETs [105], which decreased adipocyte differentiation via an increase in HO-1 expression paralleled with a decrease in PPAR $\gamma, \mathrm{C} / \mathrm{EBP} \alpha$ and FAS levels, suggesting that EETs can regulate lipid metabolism in developing preadipocytes so as to inhibit and/or delay adipocyte differentiation [133]. And EET could increase adipocyte proliferation by phenotypically reprogramming adipocytes to decrease the expression of PPAR $\gamma$ and mesodermspecific transcript (MEST), and form a module to switch to genetically reprogram the adipocyte phenotype to express less MEST and prevent hypoadiponectinemia $[57,131,133]$. Moreover, treat human MSCs with adipogenic media for two-week and bind with an additional $10 \mathrm{mM}$ of glucose (hyperglycemic conditions) lead to an increase in adipogenic differentiation. While adipogenic differentiation decreased with the treatment of CoPP, demonstrating the predominance of preadipocytes, indicating the influence of $\mathrm{HO}-1$ in the regulation of genes controlling adipocyte differentiation [134]. Therefore, MSC-derived adipocytes are not only a production of environmental stimuli and the right balance in ROS, but also the interaction of $\mathrm{HO}$ and EET contribute to adipogenesis and adipocyte function (Figure 4).

\section{Impact of EET and HO-1on Obesity Induced Hypertension}

Obesity is known to relate with an increase in sodium retention and volume expansion, which are the risk factors contribute to hypertension [135]. And Theken studied the relevance of EETs with hypertension in obese patients with or without CAD, and indicated that patients with obesity are associated with a low level of EET, and the CYP epoxygenase activity is suppressed and sEH metabolic activity is increased [136]. And it was studied that treat obese HO-2 KO mice with EET agonist could increase EET levels in kidney and vascular, with lowered blood pressure and decreased body weight gain and reduced subcutaneous and visceral fat, associated with an increase insulin sensitivity [106].

EETs, both autocrine and paracrine mediators, play an important role in the cardiovascular and renal systems [137]. Due to the strong vasodilatory actions within the endothelium and kidney, EETs act as an endothelium derived hyperpolarizing factor (EDHF) [138]. EETs dilate the preglomerular arterioles through $\mathrm{Ca}(2+)$-activated $\mathrm{K}(+)$ channels in renal smooth muscle cell and hyperpolarize smooth muscle cells [139]. And EETs is also the second messengers for many paracrine and

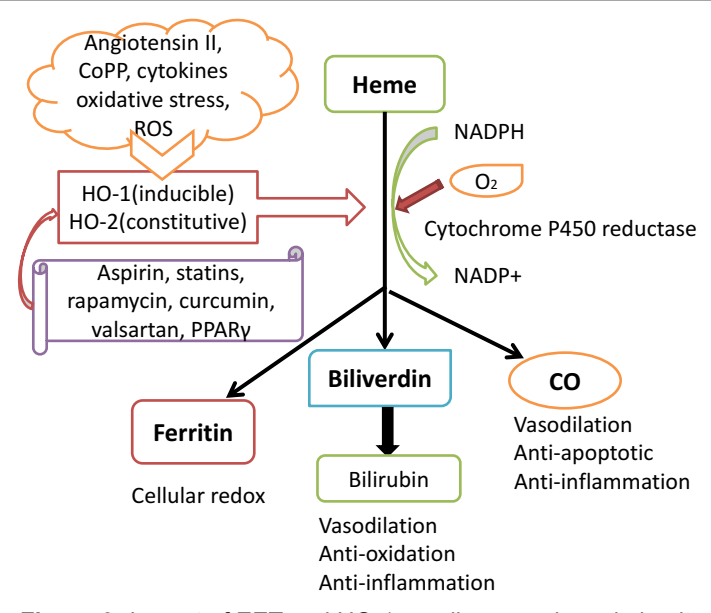

Figure 3: Impact of EET and HO-1on adipogenesis and obesity. 
hormonal agents such as vasodilatory substances, namely endothelin, angiotensin, NO, and PGI2.

It is known that the pleiotropic effects of EET could upregulate HO activity, and HO system could increase EET and adiponectin [140]. The antioxidant action of $\mathrm{HO}$ metabolites is related to extension of small adipocyte which associated with an increased adiponectin and its downstream signals including pAMPK, peNOS and induced NO bioavailability $[141,142]$. Upregulation of these pathways could improve vascular function and dominate of hypertension, and the increase in biliverdin from HO-1 could prevent EET from degradation by ROS and adiponectin [121]. Moreover, HO-derived CO is a vasodilator, which could regulate basal and constrictor induced vascular tone in blood vessels [143]. And study showed that chronic CO treatment with a CO-releasing molecule (CORM) could protect vascular function [144]. High fat diet rats treated with CORM-A1-derived CO showed decrease in body fat, insulin and fasting blood glucose, while with increase in oxygen consumption and heat production [145].

These results establish the interdependence of EET and HO-1 in preventing obesity and associated hypertension, activation of these pathways could protect the vasculature against damage associated with vascular disease (Figure 4 ).

\section{Impact of EET and HO-1 on Obesity Induced Endothelial Dysfunction and Arthrosclerosis}

Endothelial cell dysfunction, verified by the diminished expression of CD31+ and/or thrombomodulin (TM) [146], located within atherosclerotic blood vessels, indicating an early feature of chronic cardiovascular diseases [147], and related to extra levels of ROS [148]. The abnormality of CD31+ gene was showed in the pathogenesis of both atherosclerosis and myocardial infarction, whereas a reduction in plasma TM was linked to an increased risk of myocardial infarction [149]. Reduced expression of CD31+ and TM in endothelial cells indicated endothelial cell death, associating with the progression of atherosclerotic heart disease [146], and the restoration of their expression could benefit atherosclerosis and myocardial infarction [149].

Inflammation, as well as endothelial cells injury, is critical contributor to atherosclerosis [150], the upregulation of IL-6 and TNF- $\alpha$ induced by chronic stress and angiotensin II leading to atherosclerosis [151]. Studies indicated that HO-1 suppress the proliferation of VSMCs through CO release [152] and inflammation

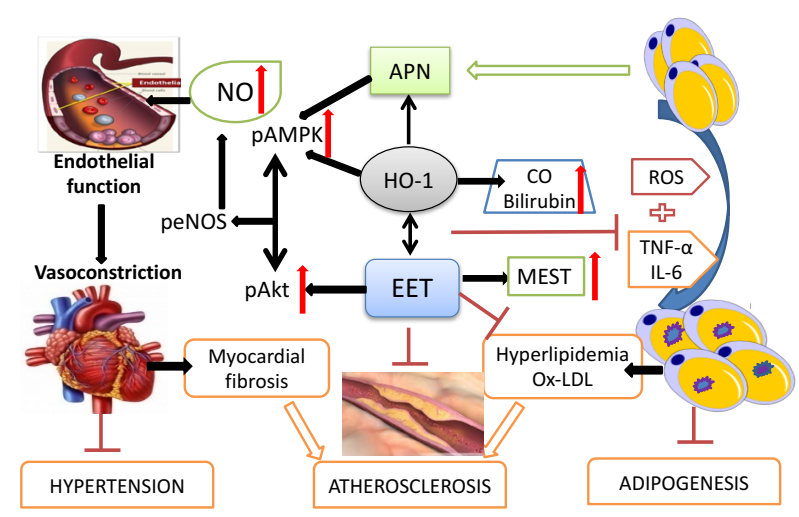

Figure 4: Expression and activity, altered inflammation and reverse endothelial function, so as to prevent atherosclerosis. alteration [153]. Monocyte chemoattractant protein-1(MCP-1) as a strong chemoattractant for macrophages turn mononuclear cells into macrophages, and nuclear factors adjust the MCP-1 transcription and expression in atherosclerotic plaque [154]. And HO-1 pathway could regulate MCP-1 secretion and ICAM-1 expression. Products of $\mathrm{HO}$ metabolism of heme, bilirubin and $\mathrm{CO}$, upregulate EC-SOD and decrease inducible enzymes as seen in iNOS and peroxynitrite generation, and act as a countervailing influence to hyperglycemiamediated injury in endothelial cells and in sloughing. We have also shown that decrease in iNOS and increase in EC-SOD mediated by HO-1 derived $\mathrm{CO}$ and biliverdin/bilirubin exerts beneficial actions in vascular protection [155].

Atherosclerosis, a progressive disease characterized by the accumulation of lipids and fibrous components in the arteries, is the major cause of mortality worldwide [156]. Widespread epidemiological evidence strongly verified the connection between the plasma cholesterol profile and the development of atherosclerosis. It indicated that high-density lipoprotein (HDL) is effectively protective against atherosclerosis, whereas low-density lipoprotein (LDL), especially oxidized (ox-) LDL, act as a trigger of atherosclerosis [157]. LDL stimulates the inflammatory response and formation of foam cells, which are fat-laden macrophages that form the fatty streaks in plaques [158]. Soluble epoxide hydrolase inhibitors could increase EET levels and reduce atherosclerotic lesion formation in mice deficient in apolipoprotein (apo) E or LDL receptor [159]. apoE-/- mice displayed advanced lesions and an obvious upregulation in the LDL/HDL ratio, and administration of sEH inhibitor extensively shrunk serum LDL concentrations and secretion of inflammatory factors [160]. And recent studies in adipose tissue have confirmed that the administration of sEH inhibitor ( $\mathrm{t}$-AUCB) develops the CD36-mediated recognition and ox-LDL degradation and improves cholesterol efflux by inducing ATP-binding cassette A1(ABCA1) expression [161], and ABCA1 subsequently enhanced plasma HDL concentrations and reversed cholesterol transport [162], which may also play a part factor of antiatherosclerotic effect. Meanwhile EETs accumulated in the occurrence of the $\mathrm{sEH}$ inhibitor and activated peroxisome proliferator-activated receptor (PPAR) $\gamma$, which may be involved in $\mathrm{sEH}$ inhibition-induced CD36 and ABCA1 expression [162]. Moreover, EET upregulation could induce HO-1 expression and activity, altered inflammation and reverse endothelial function, so as to prevent atherosclerosis (Figure 4).

\section{Impact of EET and HO-1 on Obesity Mitochondrial Function}

Marked mitochondrial dysfunction has been observed in myocardial cells in cardiovascular diseases [163], and improve mitochondrial function is associated with an improvement in myocardial function. More than $50 \%$ of disease-related mutations in mitochondrial DNA result in cardiomyopathy in humans, and targeted mutations disturbing fatty acid transport and oxidation, high-energy phosphate transport and shutting. Protection from mitochondrial ROS, and mitochondrial DNA proofreading activity all cause profound cardiac dysfunction [164].

As the intermediary between EET and HO-1, PGC-1a could establish homeostatic energy metabolism, normalize mitochondrial quality, upregulate mitochondrial biogenesis and respiration, adaptive thermogenesis and gluconeogenesis as well as many other metabolic processes through the activation of AMPK and SIRT $[165,166]$. The upregulation of this energy sensing network can stimulate the ROS formation reduction [167]. And PGC-1 $\alpha$ is vital to the amputation of mitochondrial ROS through regulation of the expression of plentiful enzymes that provoke ROS $[168,169]$. Novel statistics indicated 
that PGC1a-knockdown mice have an increased exposure to neurodegeneration and hippocampus-situated oxidative stress [170]. It was reported that endogenous SIRT3-deficient showed an increased intracellular ROS, while upregulation of SIRT3 could alleviated ROS in brown adipocytes and reestablished uncoupling proteins UCP thermogenesis [87]. UCP1 and UCP2 from adipose tissue could control of energy as heat and affect energy metabolism efficiency [25]. Superior SIRT1 levels could reduce NF- $\kappa \beta$ inflammatory transcription and result in increase the level of PGC-1 $\alpha[85,171]$, which act as a potent suppressor of ROS through the stimulation of ERR $\alpha$ and the consequent generation of ROS detoxifying agents GPx1 and SOD2 [172].

PGC1a could stimulate biogenesis and restore mitochondrial quality control through the transcriptional co-activation of nuclear respiratory factor (NRF)-1/2 [173]. NRF-1 and NRF-2 enhance mitochondrial transcription factor A (TFAM) localization to the mitochondria, resulting in augmented mitochondrial biogenesis and respiration, so as to a simultaneous rise in cytochrome C and ATPase [174]. TFAM elevation is important in the PGC1 $\alpha$-facilitation of mtDNA replication [164]. Based on the role of mitochondrial dysfunction played in ROS production underlying metabolic syndrome, PGC1 $\alpha$ and concomitant SIRT have major implications in the therapeutic mitochondrial targeting of obesity, DM, and cardiovascular dysfunction indexes $[175,176]$.

\section{Impact of EET and HO-1 on Obesity Induced Cardiovascular Diseases}

As Theken proved that obesity individuals have low level of EETs, and the further study presented that both obese and non-obese CAD patients had significantly higher plasma EETs with a higher epoxide/ diol ratios, demonstrating that CYP epoxygenase and sEH metabolic function are altered in patients with established atherosclerotic cardiovascular disease [136]. Treatment with EET agonist 11-(nonloxy) undec-8(z)-enoic acid (NUDSA) increases adipose tissue levels of EET and HO-1, as well as serum adiponectin in high-fat diet rats, associated with a decrease in blood pressure, subcutaneous and visceral fat content and inflammation factors (TNF- $\alpha$ and IL-6) [177]. EET was known to upregulate the expression of wntl canonical signaling cascade, attenuate cardiac dysfunction and improve angiogenesis [58]. And we know that EET could decrease NOV expression in cardiac and adipose tissue, which simultaneously increase PGC-1 $\alpha$ mediated downstream signaling, enhancing mitochondrial function and energy metabolism, and preventing the development of cardiac remodeling in cardiomyopathy [178].

EET could increase osteoblast differentiation whereas decrease adipogenesis differentiation $[140,179]$, which was further, supported by the observation that CoPP affected adipocyte differentiation in adults rats and developed in bodyweight loss without different food consumption [180]. There are many pharmacological agents which could increase HO-1 levels and decrease adiposity like the beneficial effect of CoPP, named as apolipoprotein A1 mimietic peptides L-4F, EET, and peroxisome proliferator-activated receptor (PPAR), which also lead to a decrease in visceral subcuntaneous fat and an increase in insulin sensitivity [181-184], associated with the reduction of large adipocytes number and a lift of smaller healthy adipocytes $[133,185,178]$.

Enhanced EET has been indicated to reduce myocardial fibrosis and inflammation, so as to reduce hypertrophy and improve diastolic function of metabolic syndrome rats [186]. Aortic endothelial function, peNOS expression and adipose tissue markers of energy homeostasis such as pAMPK, pAkt, Sirt1, and fatty acid synthase (FAS), are restored in animals with NUDSA treatment $[177,187,188]$. As EET can upregulate HO-1, and we found out that CoPP induction of HO-1 decreased circulating free fatty acids and C-reactive protein, increased adiponectin, through the activation of AMPK-P13K-eNOS pathway $[185,189]$, and adiponectin concentration in human plasma is lower in patients with clinical manifestations of CAD than in BMI- and age-adjusted control subjects independent of other risk factors $\{1508\}$ [190], while high adiponectin adiponectin is related to a lower risk of CAD in male diabetic patients $\{1567\}$ [191] It should be highlight that HO-1 could not increase adiponectin directly, but through HO-1 mediated antioxidant mechanism with a decreased in heme associated with increase in superoxide dismutase, which reduce ROS levels and increase adiponectin[176,181,192,193].

And PGC-1 $1 \alpha$ has been addressed to control many aspects of oxidative metabolism, including mitochondrial biogenesis and respiration through coactivation of many nuclear receptors [194]. In cardiac cells PGC-1 1 could induce abundantly of genes, programming for critical enzymes in major metabolic programs required for high-efficiency ATP production [195,196], and it could upregulate over $70 \%$ of the subnets in the mitochondrial electron transport chain and the ATPase complexes, and markedly increase fatty acid oxidation [197,198]. PGC1a expression is stimulated by ischemic conditions in cell culture, and a PGC-1 $\alpha$ transcriptional coactivators have now arose as a dominant regulator of mitochondrial biology in the heart, and the expression of PGC-1 $\alpha$ is suppressed in numerous heart failure diseases $[199,200]$. Pathologically hypertrophied heart induced by the coarctation of the aorta, have a decreased expression of both PGC-1 $\alpha$ and its target genes of fatty acid oxidation and oxidative phosphorylation [201,202]. And after PGC-1 $\alpha$ knockout, the heart isolated from the mice showed decreased fatty acid oxidation and heart function reduction, and the myocardial fibers presented decreased ATP synthesis rates and ATP production efficiency $[203,204]$. Structural analysis demonstrated an abnormal mitochondrial cristae density and cytoplasmic accumulation of lipids, indicating a reduction in fatty acid consumption paralleled with lipotoxicity from increase fatty acid uptake [203]

Moreover, PGC-1 $\alpha$ also appears to mediate EET-induced HO-1 activity upregulation [178,205], this mechanism has been observed categorically in adipose tissue suggesting the activity of EET in the vasculature and in the myocardium in cardiovascular diseases (Figure $5)$.

\section{Soluble Epoxide Hydrolase Inhibitor and Clinical Therapy}

Soluble epoxide hydrolase ( $\mathrm{sEH}$ ) could degrade epoxides into corresponding diols, which are substantially less active than the original compound. Inhibition of sEH leads to EETs accumulation and retention in various tissues [206,207], which have anti-inflammation function, vasodilatory activity and antihypertensive action, while it can promote fibrinolysis and inhibit platelet aggregation [98, 106,208-210]. While induction of CYP-epoxygenases, administration of EET analogs, or inhibition of sEH all result in upregulation of EET concentration, and could benefit cardiovascular diseases [103]. sEH is upregulated in obesity and associated diseases, with a downregulation of EET, and decreased level of EET may lead to more sEH with lass P450epoxygenases [211], so sEH inhibitors have been extensively studied for the potential value on cardiovascular therapy.

In vitro studies, administration of $\mathrm{sEH}$ inhibitor in the MSC culture 


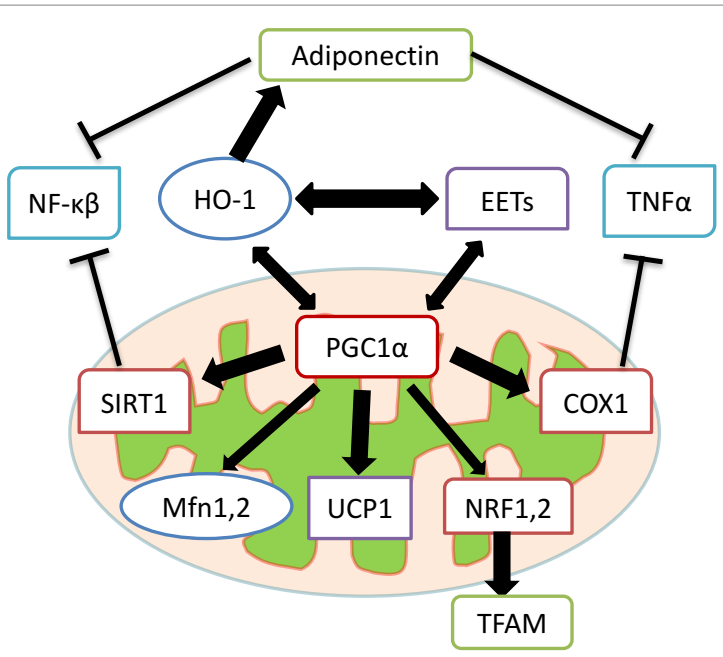

Figure 5: Adipose tissue suggesting the activity of EET in the vasculature and in the myocardium in cardiovascular diseases.

indicated a decreased adipogenesis and adiposity associated with an increased level of EET, and it was known that EET can decrease MSC-derived adipocytes [133]. And MSCs, act as pleotropic cells, can differentiate to adipocytes or osteoblasts as a result of crosstalk by specific signaling pathways including HO-1/2 expression [179]. Adipocyte stem cells treated with AUDA showed decrease in adiposity with an increased effectiveness of EET [133].

In vivo studies have indicated that $\mathrm{sEH}$ inhibition can reverse inflammation [212], reduce the development of atherosclerosis in apoplipoprotein E knowout mice [213,214], and it turned out to lower blood pressure in angiotension-dependent hypertension [215,216]. And it was studied that Glu287Arg substitution in sEH genes, in humans with familial hypercholesterolemia, is related with an increased plasma cholesterol level [217], and sEH deficiency or inhibition in high fat diet mice has been linked to the reduction of liver steatosis and attenuation of endoplasmic reticulum stress in adipose tissue $[97,218]$. Weighty testing of $s E H$ inhibitors indicated they are highly selective for $\mathrm{sEH}$, lack significant toxicity, and have potential for use in humans $[219,220]$. Moreover, the connotation between sEH and vascular phenotypes has been investigated in 106 patients with stable $\mathrm{CAD}$, and there was a significant inverse relationship between 20-HETE levels and brachial artery flow-mediated dilation, paralleling with an inverse relationship between $\mathrm{sEH}$ function and a combination of MCP-1 and cellular adhesion molecule score, indicating that sEH therapy might be effective in human vascular dysfunction [221].

GSK2256294A is a reversible binding inhibitor of isolated recombinant humansEH, exhibiting a good preclinical pharmacokinetic profile with high oral bioavailability in mice [222]. Concurrently, it has been detected to reduce the inflammatory response induced by repetitive exposures to cigarette smoke, indicating its dose-dependent effect with sustaining for up to 24 hours [223]. And it has the promise to become one of the vital treatment for obesity and associated diseases.

\section{Conclusion}

The obesity associated cardiovascular diseases relies heavily on EET system, implementation of the EETs in pharmaceutical synthetics may comprise a novel avenue for the treatment of metabolic insults through the restoration of mitochondrial integrity and associated adiposity. The capacity of EET with induced HO- 1 could decrease inflammatory cytokines, angiotensin II and oxidative stress, finally lead to heart function improvement, rendering it a noticeable target for clinical application. The pleiotropic effect of EET synchronously contrast the multifactorial etiology of obesity and associated cardiovascular diseases, and it acts like a master regulator of multiple components of myocardial energetics through the crosstalk with both PGC-1 $\alpha$ and HO1. sEH inhibitor therapy has been test in vitro and in vivo in animals, as well as in human preclinical trials to value the adverse effects of EET. As such, the application of the EET-HO-1 module in a clinical setting may potentially serve as a potent approach to combatting the unabated global epidemic of obesity and associated cardiovascular diseases.

\section{References}

1. Gesta S, Tseng YH, Kahn CR (2007) Developmental origin of fat: Tracking obesity to its source. Cell 131: 242-256.

2. Wang R, Li XN (2017) Different adipose tissue depots and metabolic syndrome in human. Acta Physiologica Sinicavol 69: 357-365.

3. Cleal L, Aldea T, Chau YY (2017) Fifty shades of white: Understanding heterogeneity in white adipose stem cells. Adipocyte 6: 205-216.

4. Billon N, Dani C (2012) Developmental origins of the adipocyte lineage: new insights from genetics and genomics studies. Stem Cell Rev 8: 55-66.

5. Scheele C, Nielsen S (2017) Metabolic regulation and the anti-obesity perspectives of human brown fat. Redox Biol 12: 770-775.

6. Kajimura S, Spiegelman SP (2010) BM Transcriptional control of brown fat development. Cell Metab 11: 257-262.

7. Zietak M, Chabowska KA, Kozak LP (2016) Brown fat thermogenesis: Stability of developmental programming and transient effects of temperature and gut microbiota in adults. Biochimie 134: 93-98

8. Horowitz MC, Berry R, HoltrupB, Sebo Z (2017) Bone marrow adipocytes. Adipocyte 6: 193-204.

9. Richard D, Picard F (2011) Brown fat biology and thermogenesis. Front Biosci 16: $1233-1260$.

10. Yasmeen R, Jeyakumar SM, Reichert B, Yang F (2011) The contribution of vitamin $A$ to autocrine regulation of fat depots. Biochim et Biophysica Acta 1821: 190-197.

11. Rajakumari S, Wu J, Ishibashi J, Lim HW (2013) EBF2 determines and maintains brown adipocyte identity. Cell Metab 17: 562-574.

12. Akerblad P, Mansson R, Lagergren A, Westerlund S (2005) Gene expression analysis suggests that EBF-1 and PPARgamma2 induce adipogenesis of $\mathrm{NIH}$ 3T3 cells with similar efficiency and kinetics. Physiol Genomics 23: 206-216.

13. Tentolouris $N$, Liatis $S$, Katsilambros $N$ (2006) Sympathetic system activity in obesity and metabolic syndrome. Ann NY Acad Sci 1083: 129-152.

14. Maric C, Hall JE (2011) Obesity, metabolic syndrome and diabetic nephropathy Contrib Nephrol 170: 28-35.

15. Lopaschuk GD, Folmes CD, Stanley WC (2007) Cardiac energy metabolism in obesity. Circ Res 101: 335-347.

16. Lopez E F, Kabarowski JH, Ingle KA, Kain V (2015) Obesity superimposed on aging magnifies inflammation and delays the resolving response after myocardial infarction. Am J Physiol Heart Circ Physiol 308: H269-H280.

17. Kursawe R, Dixit VD, Scherer P E, Santoro N (2016) A role of the inflammasome in the low storage capacity of the abdominal subcutaneous adipose tissue in obese adolescents. Diabetes 65: 610-618.

18. Lumeng CN, Bodzin JL, Saltiel AR (2007) Obesity induces a phenotypic switch in adipose tissue macrophage polarization. J Clin Invest 117: 175-184.

19. Schaefer E, Winona W, Mark C, Yang A (2017) Intermittent hypoxia is a proinflammatory stimulus resulting in IL-6 expression and M1 macrophage polarization. Hepatology Communications 1: 326-337.

20. Corcoran SE, O'Neill (2016) HIF1alpha and metabolic reprogramming in inflammation. J Clin Invest 126: 3699-3707.

21. Chu TD, Kozak GB (2017) Brown and brite adipocytes: Same function, but different origin and response. Biochimie 138: 102-105. 
Citation: Liu L, Huang X, Gao J, Guo Y, Di Y, et al. (2018) EET Intervention on HO-1 Prevent Obesity Derived Cardiovascular Diseases. J Biomol Res Ther 7: 163. doi:10.4172/2167-7956.1000163

Page 8 of 12

22. Thyagarajan B, Foster MT (2017) Browning of white adipose tissue as a therapeutic strategy for weight loss in humans. Horm Mol Biol Clin Investig 31: 7-10.

23. Wu J, Bostrom P, Sparks LM, Ye L (2012) Beige adipocytes are a distinct type of thermogenic fat cell in mouse and human. Cell 150: 366-376.

24. Porter C (2017) Quantification of UCP1 function in human brown adipose tissue. Adipocyte 6: 167-174.

25. Fedorenko A, Lishko PV, Kirichok Y (2012) Mechanism of fatty-acid-dependent UCP1 uncoupling in brown fat mitochondria. Cell 151: 400-413.

26. Cohen P, Spiegelman MB (2015) Brown and Beige Fat: Molecular parts of a thermogenic machine. Diabetes 64: 2346-2351.

27. Chatzigeorgiou A, Chavakis T (2016) Immune cells and metabolism. Handb Exp Pharmacol 233: 221-249.

28. Obregon MJ (2008) Thyroid hormone and adipocyte differentiation. Thyroid 18: $185-195$.

29. Jeremic N, Chaturvedi P, Tyagi SC (2017) Browning of White Fat: Novel Insight Into Factors, Mechanisms, and Therapeutics. J Cell Physiol 232: 61-68.

30. Escote X, Zorita GS, Miguel LY, Laskibar M I (2017) Role of Omentin, Vaspin, Cardiotrophin-1, TWEAK and NOV/CCN3 in obesity and diabetes development. Int J Mol Sci 18: 1770.

31. Liu X, Cervantes C, Liu F (2017) Common and distinct regulation of human and mouse brown and beige adipose tissues: A promising therapeutic target for obesity. Protein Cell 8: 446-454.

32. Kajimura S, Seale P, Kubota K, Lunsford E, Frangioni J V (2009) Initiation of myoblast to brown fat switch by a PRDM16-C/EBP-beta transcriptional complex. Nature 460: 1154-1158.

33. Cohen P, Levy JD, ZhangY, Frontini A, Kolodin DP, et al. (2014) Ablation of PRDM16 and beige adipose causes metabolic dysfunction and a subcutaneous to visceral fat switch. Cell 156: 304-316.

34. Takashima S, Nishii N, Kato A, Matsubara T, Shibata S, et al. (2016) Molecular cloning of feline resistin and the expression of resistin, leptin and adiponectin in the adipose tissue of normal and obese cats. J Vet Med Sci 78: 23-28.

35. Correia ML, Rahmouni K (2006) Role of leptin in the cardiovascular and endocrine complications of metabolic syndrome. Diabetes Obes Metab 8: 603610.

36. Gui Y, Silha JV, Murphy LJ (2004) Sexual dimorphism and regulation of resistin, adiponectin, and leptin expression in the mouse. Obes Res 12: 1481-1491.

37. Li X, Easley CJ (2018) Microfluidic systems for studying dynamic function of adipocytes and adipose tissue. Anal Bioanal Chem 410: 791-800.

38. Brodsky SV, Gealekman O, Chen J, Zhang F, Togashi N, et al. (2004) Prevention and reversal of premature endothelial cell senescence and vasculopathy in obesity-induced diabetes by ebselen. Circ Res 94: 377-384.

39. Callaghan M J, Ceradini DJ, Gurtner GC (2005) Hyperglycemia-induced reactive oxygen species and impaired endothelial progenitor cell function Antioxid Redox Signal 7: 1476-1482.

40. Clement K, Viguerie N, Poitou C, Carette C, Pelloux V, et al. (2004) Weight loss regulates inflammation-related genes in white adipose tissue of obese subjects. FASEB J 18: 1657-1669.

41. Mandavia CH, Pulakat L, DeMarco V, Sowers JR (2012) Over-nutrition and metabolic cardiomyopathy. Metabolism 61: 1205-1210.

42. Rider OJ, Cox P, Tyler D, Clarke K (2013) Myocardial substrate metabolism in obesity. Int J Obes 37: 972-979.

43. Elias I, Franckhauser S, Ferre T, Vila L, Tafuro S, et al. (2012) Adipose tissue overexpression of vascular endothelial growth factor protects against dietinduced obesity and insulin resistance. Diabetes 61: 1801-1813.

44. Santos JL, Salemi VM, Picard MH, Mady C (2011) Subclinical regional left ventricular dysfunction in obese patients with and without hypertension or hypertrophy. Obesity Silver Spring 19: 1296-1303.

45. Nakanishi K, Fukuda S, Tanaka (2017) A relationships between periventricular epicardial Adipose tissue accumulation, coronary microcirculation and left ventricular diastolic dysfunction. Can J Cardiol 33: 1489-1497.

46. Poirier P, Giles TD, Bray GA, Hong Y, Stern J, et al. (2006) Obesity and cardiovascular disease: Pathophysiology, evaluation, and effect of weight loss. Arterioscler Thromb Vasc Biol 26: 968-97.

47. Lauer MS, Anderson KM, Kannel WB, Levy D et al. (1991) The impact of obesity on left ventricular mass and geometry. The Framingham Heart Study. JAMA 266: 231-236.

48. Collins S (2014) A heart-adipose tissue connection in the regulation of energy metabolism. Nat Rev Endocrinol 10: 157-163.

49. Cassis, LA, English VL, Bharadwaj K, Boustany CM (2004) Differential effects of local versus systemic angiotensin II in the regulation of leptin release from adipocytes. Endocrinology 145: 169-174.

50. Sridharan S, Kini MR (2017) Decoding the molecular switches of natriuretic peptides which differentiate its vascular and renal functions. Biochem $\mathrm{J} 475$ 399-413.

51. Bordicchia M, Liu D, Amri EZ, Ailhaud G, ZhangC, et al. (2012) Cardiac natriuretic peptides act via p38 MAPK to induce the brown fat thermogenic program in mouse and human adipocytes. J Clin Invest 122: 1022-1036.

52. Pakradouni J, Le Goff W, Calmel C, Antoine B, Villard E, et al. (2013) Plasma NOV/CCN3 levels are closely associated with obesity in patients with metabolic disorders. PLoS One 8: e66788.

53. Hroudova J, Singh N, Fisar Z (2014) Mitochondrial dysfunctions in neurodegenerative diseases: relevance to Alzheimer's disease. Biomed Res Int 175062.

54. Tanaka T, Yoshida N, Kishimoto T, Akira S (1997) Defective adipocyte differentiation in mice lacking the C/EBPbeta and/or C/EBPdelta gene. EMBO J 16: 7432-7443

55. Won JC, Park JY, Kim YM, Koh E, Seol S, et al (2010) Peroxisome proliferatoractivated receptor-gamma coactivator 1-alpha overexpression prevents endothelial apoptosis by increasing ATP/ADP translocase activity. Arterioscler Thromb Vasc Biol 30: 290-297.

56. Hermans KC, Daskalopoulos EP, Blankesteijn WM (2012) Interventions in Wnt signaling as a novel therapeutic approach to improve myocardial infarct healing. Fibrogenesis Tissue Repair 5:16.

57. Vanella L, Sodhi K, Kim DH, Puri N, Maheshwari M, et al. (2013) Increased heme-oxygenase 1 expression in mesenchymal stem cell-derived adipocytes decreases differentiation and lipid accumulation via upregulation of the canonical Wnt signaling cascade. Stem Cell Res Ther 4: 28.

58. Cao J, Tsenovoy PL, Thompson EA, Falck JR, Touchon R, et al. (2015) Agonists of epoxyeicosatrienoic acids reduce infarct size and ameliorate cardiac dysfunction via activation of $\mathrm{HO}-1$ and Wnt1 canonical pathway. Prostaglandins Other Lipid Mediat 116-117: 76-86.

59. Nath K A, Salahudeen AK (1990) Induction of renal growth and injury in the intact rat kidney by dietary deficiency of antioxidants. J Clin Invest 86: 1179 1192.

60. McGiff JC, Vane JR (1982) Prostaglandins and the regulation of blood pressure. Kidney Int Suppl S262-S270.

61. Aldiss P, Davies G, Woods R, Budge H, Sacks HS, et al. (2017) Browning the cardiac and peri-vascular adipose tissues to modulate cardiovascular risk. Int J Cardiol 228: 265-274

62. Proud CG (2004) The multifaceted role of mTOR in cellular stress responses DNA Repair (Amst) 3: 927-934.

63. Jung U J, Choi MS (2014) Obesity and its metabolic complications: The role of adipokines and the relationship between obesity, inflammation, insulin resistance, dyslipidemia and nonalcoholic fatty liver disease. Int J Mol Sci 15 : 6184-6223.

64. Dikalov S I, Nazarewicz RR (2013) Angiotensin Il-induced production of mitochondrial reactive oxygen species: potential mechanisms and relevance for cardiovascular disease. Antioxid Redox Signal 19: 1085-1094.

65. Droge W (2002) Free radicals in the physiological control of cell function. Physiol Rev 82: 47-95.

66. Fulda S, Gorman AM, Hori O, Samali A (2010) Cellular stress responses: Cel survival and cell death. Int J Cell Biol 4: 7.

67. Gutterman DD, Chabowski DS, Kadlec AO, Durand M J, Freed JK, et al (2017) The human microcirculation: Regulation of flow and beyond. Circ Res 118: 157172. 
Citation: Liu L, Huang X, Gao J, Guo Y, Di Y, et al. (2018) EET Intervention on HO-1 Prevent Obesity Derived Cardiovascular Diseases. J Biomol Res Ther 7: 163. doi:10.4172/2167-7956.1000163

68. Croft K D, McGiff JC, Sanchez MA, Carroll MA (2000) Angiotensin II releases 20-HETE from rat renal microvessels. Am J Physiol Renal Physiol 279: F544-F551.

69. Takakura K, Ito S, Sonoda J, Tabata K, Shiozaki M, et al. (2017) Cordyceps militaris improves the survival of Dahl salt-sensitive hypertensive rats possibly via influences of mitochondria and autophagy functions. Heliyon 3: e00462.

70. Jaitovich A, Jourd'heuil D (2017) A brief overview of nitric oxide and reactive oxygen species signaling in hypoxia-induced pulmonary hypertension. Adv Exp Med Biol 967:71-81.

71. Inceoglu B, Bettaieb A, Haj FG, Gomes AV, Hammock BD, et al. (2017) Modulation of mitochondrial dysfunction and endoplasmic reticulum stress are key mechanisms for the wide-ranging actions of epoxy fatty acids and soluble epoxide hydrolase inhibitors. Prostaglandins Other Lipid Mediat 133: 68-78.

72. Chen H, Detmer SA, Ewald AJ, Griffin EE, Fraser SE, et al. (2003) and Chan, D. C., Mitofusins Mfn1 and Mfn2 coordinately regulate mitochondrial fusion and are essential for embryonic development. J Cell Biol 160: 189-200.

73. Loftin CD, Tiano HF, Langenbach R (2002) Phenotypes of the COX-deficient mice indicate physiological and pathophysiological roles for COX-1 and COX-2. Prostaglandins Other Lipid Mediat 68-69: 177-185.

74. Mitschke MM, Hoffmann LS, Gnad T, Scholz D, Kruithoff K, et al. (2013) Increased cGMP promotes healthy expansion and browning of white adipose tissue. FASEB J 27: 1621-1630.

75. Patti ME, Corvera S (2010) The role of mitochondria in the pathogenesis of type 2 diabetes. Endocr Rev 31: 364-395.

76. Srivastava $S$ (2017) The mitochondrial basis of aging and age-related disorders Genes 8: 17-20.

77. Huang TJ, Sayers NM, Verkhratsky A, Fernyhough P (2005) Neurotrophin-3 prevents mitochondrial dysfunction in sensory neurons of streptozotocindiabetic rats. ExpNeurol 194: 279-283.

78. Chalker J, Gardiner D, Kuksal N, Mailloux RJ (2018) Characterization of the impact of glutaredoxin-2 (GRX2) deficiency on superoxide/hydrogen peroxide release from cardiac and liver mitochondria. Redox Biol 15: 216-227.

79. Wei $\mathrm{H}$, Cong $X$ (2018) The effect of reactive oxygen species on cardiomyocyte differentiation of pluripotent stem cells and its potential mechanism. Free Radic Res 52: 1-201.

80. Chistiakov DA, Shkurat TP, Melnichenko AA, Grechko AV, Orekhov AN, et al. (2018) The role of mitochondrial dysfunction in cardiovascular disease: A brief review. AnnMed 50:121-127.

81. Liu Z, Gu H, Gan L, Xu Y, Feng F, et al. (2017) Reducing Smad3/ATF4 was essential for Sirt1 inhibiting ER stress-induced apoptosis in mice brown adipose tissue. Oncotarget 8: 9267-9279.

82. Jukarainen S, Heinonen S, Ramo JT, Rappou E, Tummers M, et al. (2016) Obesity is associated with low $\mathrm{NAD}(+) / \mathrm{SIRT}$ pathway expression in adipose tissue of bmidiscordant monozygotic twins. J Clin Endocrinol Metab 101: 275-283.

83. Salminen A, Kaarniranta K (2012) AMP-activated protein kinase (AMPK) controls the aging process via an integrated signaling network. Ageing Res Rev 11: 230-241.

84. Belcher JD, Vineyard JV, Bruzzone CM, Chen C, Beckman, et al. (2010) Heme oxygenase-1 gene delivery by Sleeping Beauty inhibits vascular stasis in a murine model of sickle cell disease. JMol Med 88: 665-675.

85. Ruderman NB, Carling D, Prentki M, Cacicedo JM (2013) AMPK, insulin resistance, and the metabolic syndrome. J Clin Invest 123: 2764-2772.

86. Lee JW, Choe SS, Jang H, Kim J, Jeong H, et al. (2012) AMPK activation with glabridin ameliorates adiposity and lipid dysregulation in obesity. J Lipid Re 53: 1277-1286.

87. Hirschey MD, Shimazu T, Goetzman E, Jing E, Schwer B, et al. (2010) SIRT3 regulates mitochondrial fatty-acid oxidation by reversible enzyme deacetylation. Nature 464: 121-125.

88. Valko M, Leibfritz D, Moncol J, Cronin MT, Mazur M, et al. (2007) Free radicals and antioxidants in normal physiological functions and human disease. Int $J$ Biochem Cell Biol 39: 44-84.

89. Sozio MS, Lu C, Zeng Y, Liangpunsakul S, Crabb DW, et al. (2011) Activated AMPK inhibits PPAR-\{alpha\} and PPAR-\{gamma\} transcriptional activity in hepatoma cells. Am J Physiol Gastrointest Liver Physiol 301: G739-G747.
90. Wanders RJ, Vreken P, den Boer ME, Wijburg FA, van Gennip AH, et al. (1999) Disorders of mitochondrial fatty acyl-CoA beta-oxidation. J Inherit Metab Dis 22: $442-487$.

91. Martins AR, Nachbar RT, Gorjao R, Vinolo MA, Festuccia WT, et al. (2012) Mechanisms underlying skeletal muscle insulin resistance induced by fatty acids: importance of the mitochondrial function. Lipids Health Dis 11: 30 .

92. Spector AA, Fang X, Snyder GD, Weintraub NL (2004) Epoxyeicosatrienoic acids (EETs): metabolism and biochemical function. Prog Lipid Res 43: 55-90.

93. Huang $\mathrm{H}$, Weng J, Wang MH (2016) EETs/sEH in diabetes and obesity-induced cardiovascular diseases. Prostaglandins Other Lipid Mediat 125: 80-89.

94. Chaudhary KR, Zordoky BN, Edin ML, Alsaleh N, El-Kadi, et al. (2013) Differential effects of soluble epoxide hydrolase inhibition and CYP2J2 overexpression on postischemic cardiac function in aged mice. Prostaglandins Other Lipid Mediat 104-105: 8-17.

95. Norris PC, Dennis EA (2012) Omega-3 fatty acids cause dramatic changes in TLR4 and purinergic eicosanoid signaling. ProcNatl Acad Sci 109: 8517-8522.

96. Aghazadeh-Habashi, Asghar W, Jamali F (2018) Drug-disease interaction Effect of inflammation and nonsteroidal anti-inflammatory drugs on cytochrome p450 metabolites of arachidonic acid. J Pharm Sci 107: 765-763.

97. Romashko M, Schragenheim J, Abraham NG, McClung JA (2016) Epoxyeicosatrienoic acid as therapy for diabetic and ischemic cardiomyopathy. Trends Pharmacol Sci 37: 945-962.

98. Jamieson KL, Endo T, Darwesh AM, Samokhvalov V, (2017) Cytochrome P450derived eicosanoids and heart function. Pharmacol Ther 179: 47-83.

99. Imig JD, Elmarakby A, Nithipatikom K, Wei S, Capdevila JH, et al. (2010) Development of epoxyeicosatrienoic acid analogs with in vivo anti-hypertensive actions. Front Physiol 1: 157-

100.Snider NT, Kornilov AM, Kent UM, Hollenberg PF (2007) Anandamide metabolism by human liver and kidney microsomal cytochrome p450 enzymes to form hydroxyeicosatetraenoic and epoxyeicosatrienoic acid ethanolamides. J Pharmacol Exp Ther 321: 590-597.

101. Shahabi P, Siest G, Meyer UA, Visvikis-Siest S (2014) Human cytochrome P450 epoxygenases: variability in expression and role in inflammation-related disorders. Pharmacol Ther 144: 134-161.

102. Pomposiello SI, Quilley J, Carroll MA, Falck JR (2003) 5,6-epoxyeicosatrienoic acid mediates the enhanced renal vasodilation to arachidonic acid in the SHR. Hypertension 42: 548-554

103.Imig JD (2012) Epoxides and soluble epoxide hydrolase in cardiovascular physiology. Physiol Rev 92: 101-130.

104. Kim HS, Kim SK, Kang KW (2017) Differential effects of seh inhibitors on the proliferation and migration of vascular smooth muscle cells. Int J Mol Sci 18.

105. Burgess A, Vanella L, Bellner L, Schwartzman ML (2012) Epoxyeicosatrienoic acids and heme oxygenase- 1 interaction attenuates diabetes and metabolic syndrome complications. Prostaglandins Other Lipid Mediat 97: 1-16.

106. Sodhi K, Inoue K, Gotlinger KH, Canestraro M, Vanella L, et al. (2009) Epoxyeicosatrienoic acid agonist rescues the metabolic syndrome phenotype of HO-2-null mice. J Pharmacol Exp Ther 331: 906-916.

107.Drummond GS, Kappas A (1982) Chemoprevention of neonatal jaundice: Potency of tin-protoporphyrin in an animal model. Science 217: 1250-1252.

108. Abraham NG, Drummond GS, Lutton JD, Kappas A (1996) The biological significance and physiological role of heme oxygenase. Cell Physiol Biochem 6: 129-168.

109. Abraham NG, Kappas A (2008) Pharmacological and clinical aspects of heme oxygenase. Pharmacol Rev 60: 79-127.

110. Merkel C, Bolognesi M, Bellon S, Sacerdoti D, Bianco S, et al. (1992) Longterm follow-up study of adult patients with non-cirrhotic obstruction of the portal system: Comparison with cirrhotic patients. J Hepatol 15: 299-303.

111. Balla J, Jacob HS, Balla G, Nath K, Eaton JW, et al. (1993) Endothelial-cell heme uptake from heme proteins: induction of sensitization and desensitization to oxidant damage. Proc Natl Acad Sci USA 90: 9285-9289.

112. Hall JE (2003) The kidney, hypertension and obesity. Hypertension 41: 625-633.

113. Ogden CL, Carroll MD, Curtin LR, McDowell MA, Tabak CJ, et al. (2006) Prevalence of overweight and obesity in the United States, 1999-2004. JAMA 295: 1549-1555. 
Citation: Liu L, Huang X, Gao J, Guo Y, Di Y, et al. (2018) EET Intervention on HO-1 Prevent Obesity Derived Cardiovascular Diseases. J Biomol Res Ther 7: 163. doi:10.4172/2167-7956.1000163

114. Fontana L, Eagon JC, Trujillo ME, Scherer PE (2007) Visceral fat adipokine secretion is associated with systemic inflammation in obese humans. Diabetes 56: 1010-1013.

115. Li M, Kim DH, Tsenovoy PL, Peterson SJ, Rezzani R, et al. (2008) Treatment of obese diabetic mice with a heme oxygenase inducer reduces visceral and subcutaneous adiposity, increases adiponectin levels, and improves insulin sensitivity and glucose tolerance. Diabetes 57: 1526-1535.

116. Briggs DB, Jones CM, Mashalidis EH, Nunez M, Hausrath AC, et al. (2008) Disulfide-dependent self-assembly of adiponectin octadecamers from trimers and presence of stable octadecameric adiponectin lacking disulfide bonds in vitro. Biochemistry (Mosc) 48: 12345-12357.

117. Wang R (2010) The Evolvement of Gasotransmitter Biology and Medicine: From Atmospheric Toxic Gases to Endogeous Gaseous Signaling Molecules 39: 3-32.

118. Juncos JP, Grande JP, Murali N, Croatt AJ, Juncos LA, et al. (1987) Bilirubin is an antioxidant of possible physiological importance. Science 235: 1043-1046.

119. Karadag F, Sengul CB, Enli Y, Karakulah K, Alacam H, et al. (2017) Relationship between serum bilirubin levels and metabolic syndrome in patients with schizophrenia spectrum disorders. Clin Psychopharmacol. Neurosci 15: $153-$ 162.

120. Neuzil J, Stocker R (1994) Free and albumin-bound bilirubin are efficient coantioxidants for alpha-tocopherol, inhibiting plasma and low density lipoprotein lipid peroxidation. J Biol Chem 269: 16712-16719.

121. Abraham NG, Kappas A (2005) Heme oxygenase and the cardiovascularrenal system. Free Radic Biol Med 39: 1-25.

122. Vitek L (2012) The role of bilirubin in diabetes, metabolic syndrome and cardiovascular diseases. Front Pharmacol 3: 55.

123. Kotiadis VN, Duchen MR, Osellame LD (2014) Mitochondrial quality control and communications with the nucleus are important in maintaining mitochondrial function and cell health. Biochim Biophys Acta 1840: 1254-1265.

124. Corna G, Santambrogio P, Minotti G, Cairo G (2004) Doxorubicin paradoxically protects cardiomyocytes against iron-mediated toxicity: Role of reactive oxygen species and ferritin. J Biol Chem 279: 13738-13745.

125. Gonzales S, Erario MA, Tomaro ML (2002) Heme oxygenase-1 induction and dependent increase in ferritin. A protective antioxidant stratagem in hemintreated rat brain. Dev Neurosci 24: 161-168.

126. Orino K, Lehman L, Tsuji Y, Ayaki H, Torti SV, et al. (2001) Ferritin and the response to oxidative stress. Biochem J 357: 241-247.

127. Elias D, Markovits D, Reshef T, van der Zee, Cohen IR (1990) Induction and therapy of autoimmune diabetes in the non-obese diabetic (NOD/Lt) mouse by a 65-kDa heat shock protein. Proc Natl Acad Sci 87: 1576-1580.

128. Yang G, Nguyen X, Ou J, Rekulapelli P, Stevenson DK, et al. (2001) Unique effects of zinc protoporphyrin on HO-1 induction and apoptosis. Blood 97: 1306-1313,

129. Furukawa S, Fujita T, Shimabukuro M, Iwaki M, Yamada Y, et al. (2004) Increased oxidative stress in obesity and its impact on metabolic syndrome. J Clin Invest 114: 1752-1761.

130. Imhoff BR, Hansen JM (2010) Extracellular redox environments regulate adipocyte differentiation. Differentiation 80: 31-39.

131. Vanella L, Kim DH, Sodhi K, Barbagallo I, Burgess AP, et al. (2011) Crosstalk between EET and $\mathrm{HO}-1$ downregulates Bach1 and adipogenic marker expression in mesenchymal stem cell derived adipocytes. Prostaglandins Other Lipid Mediat 96: 54-62.

132. Capdevila JH, Falck JR, Imig JD (2007) Roles of the cytochrome P450 arachidonic acid monooxygenases in the control of systemic blood pressure and experimental hypertension. Kidney Int 72: 683-689.

133. Kim DH, Vanella L, Inoue K, Burgess A, Gotlinger K, et al. (2010) Epoxyeicosatrienoic acid agonist regulates human mesenchymal stem cellderived adipocytes through activation of HO-1-pAKT signaling and a decrease in PPARgamma. Stem Cells Dev 19: 1863-1873.

134. Kim DH, Burgess AP, Li M, Tsenovoy PL, Addabbo F, et al. (2008) Heme oxygenase-mediated increases in adiponectin decrease fat content and inflammatory cytokines, tumor necrosis factor-alpha and interleukin-6 in Zucker rats and reduce adipogenesis in human mesenchymal stem cells. J Pharmacol Exp Ther 325: 833-840.
135. Sgambat K, Clauss S, Lei KY, Song J, Rahaman SO, et al. (2017) Effects of obesity and metabolic syndrome on cardiovascular outcomes in pediatric kidney transplant recipients: A longitudinal study. Pediatr Nephrol.

136. Theken KN, Schuck RN, Edin ML, Tran B, Ellis K, et al. (2012) Evaluation of cytochrome P450-derived eicosanoids in humans with stable atherosclerotic cardiovascular disease. Atherosclerosis 222: 530-536.

137. Imig JD (2015) Epoxyeicosatrienoic acids, hypertension, and kidney injury. Hypertension 65: 476-482.

138. Sudhahar V, Shaw S, Imig JD (2010) Epoxyeicosatrienoic acid analogs and vascular function. Curr Med Chem 17: 1181-1190.

139. Marin-Garcia J, Goldenthal M J (2008) Mitochondrial centrality in heart failure Heart Fail Rev 13: 137-150.

140. Burgess AP, Vanella L, Bellner L, Gotlinger K (2012) Heme oxygenase (HO1) rescue of adipocyte dysfunction in $\mathrm{HO}-2$ deficient mice via recruitment of epoxyeicosatrienoic acids (EETs) and adiponectin. Cell Physiol Biochem 29: 99-110.

141. Abraham NG, Sodhi K, Silvis AM, Vanella L (2014) CYP2J2 targeting to endothelial cells attenuates adiposity and vascular dysfunction in mice fed a high-fat diet by reprogramming adipocyte phenotype. Hypertension 64: 1352 1361

142. Kusmic C, L'Abbate A, Sambuceti G, Drummond G (2010) Improved myocardial perfusion in chronic diabetic mice by the up-regulation of pLKB1 and AMPK signaling. J Cell Biochem 109: 1033-1044.

143. Leffler CW, Nasjletti A, Johnson RA, Fedinec AL (2001) Contributions of prostacyclin and nitric oxide to carbon monoxide- induced cerebrovascular dilation in piglets. Am J Phyisiol Heart Circ Physiol 280: H1490-H1495,

144. Hosick PA, AIAmodi AA, Hankins MW, Stec DE (2015) Chronic treatment with a carbon monoxide releasing molecular revereses dietary induced obesity in mice. Adipocyte 5: 1-10.

145. Hosick PA, AIAmodi AA, Storm MV, Gousset MU, Pruett BE, et al. (2013) Chronic carbon monoxide treatment attenuates development of obesity and remodels adipocytes in mice fed a high-fat diet. Int J Obes (Lond) 38: 132-139.

146. Sandusky G, Berg DT, Richardson MA, Myers L, Grinnell BW (2002) Modulation of thrombomodulin-dependent activation of human protein $C$ through differential expression of endothelial Smads. J Biol Chem 277: 4981549819 .

147. Meigs JB (2004) Biomarkers of endothelial dysfunction and risk of type 2 diabetes mellitus. JAMA 291: 1978.

148. Ohara Y, Peterson TE, Harrison DG (1993) Hypercholesterolemia increases endothelial superoxide anion production. J Clin Invest 91: 2546-2551.

149. Morange PE, Simon C, Alessi MC, Luc G, Arveiler D, et al. (2004) Endothelial cell markers and the risk of coronary heart disease: The Prospective Epidemiological Study of Myocardial Infarction (PRIME) study. Circulation 109: 1343-1348.

150. Momiyama Y, Adachi H, Fairweather D, Ishizaka N, (2014) Inflammation, atherosclerosis and coronary artery disease. Clin Med Insights Cardiol 8s 3 CMC. 539423

151. Ji Y, Liu J, Wang Z, Liu N (2009) Angiotensin II induces inflammatory response partly via toll-like receptor 4-dependent signaling pathway in vascular smooth muscle cells. Cell Physiol Biochem 23: 265-276.

152. Otterbein LE, Zuckerbraun BS, Haga M, Liu F, Song R, et al. (2003) Carbon monoxide suppresses arteriosclerotic lesions associated with chronic graft rejection and with balloon injury. Nat Med 9: 183-190.

153. Kuhn AM, Tzieply N, Schmidt MV, von Knethen A, Namgaladze D, et al (2011) Antioxidant signaling via Nrf2 counteracts lipopolysaccharide-mediated inflammatory responses in foam cell macrophages. Free Radic Biol Med 50: 1382-1391.

154. Tacke F, Alvarez D, Kaplan TJ, Jakubzick C, Spanbroek R, et al. (2007) Monocyte subsets differentially employ CCR2, CCR5, and CX3CR1 to accumulate within atherosclerotic plaques. J Clin Invest 117: 185-194.

155.Zhang X, Shan P, Alam J, Fu XY, (2004) Carbon monoxide differentially modulates STAT1 and STAT3 and inhibits apoptosis via a phosphatidylinositol 3-kinase/Akt and p38 kinase-dependent STAT3 pathway during anoxiareoxygenation injury. J Biol Chem 280: 8714-8721. 
Citation: Liu L, Huang X, Gao J, Guo Y, Di Y, et al. (2018) EET Intervention on HO-1 Prevent Obesity Derived Cardiovascular Diseases. J Biomol Res Ther 7: 163. doi:10.4172/2167-7956.1000163

156. Santoro L, De Matteis G, Fuorlo M, Giupponi B, Martone AM, et al. (2017) Atherosclerosis and cardiovascular involvement in celiac disease: The role of autoimmunity and inflammation. Eur Rev Med Pharmacol Sci 21: 5437-5444.

157.Kopin L, Lowenstein C (2017) Dyslipidemia. Ann Intern Med 167: ITC81. ITC96.

158. Ulu A, Davis BB, Tsai HJ, Kim IH, Morisseau C, et al. (2008) Soluble epoxide hydrolase inhibitors reduce the development of atherosclerosis in apolipoprotein e-knockout mouse model. J Cardiovasc Pharmacol 52: 314323.

159. Jiang JX, Zhang SJ, Xiong YK, Jia YL, Sun YH, et al. (2015) EETs attenuate Ox-LDL-induced LTB4 production and activity by inhibiting p38 MAPK phosphorylation and 5-LO/BLT1 receptor expression in rat pulmonary arterial endothelial cells. PLoS One 10: e0128278.

160.Zhang LN, Vincelette J, Cheng Y, Mehra U, Chen D, et al. (2009) Inhibition of soluble epoxide hydrolase attenuated atherosclerosis, abdominal aortic aneurysm formation, and dyslipidemia. Arterioscler. Thromb Vasc Biol 29 : $1265-1270$.

161. Xu DY, Davis BB, Wang ZH, Zhao SP, Wasti B, et al. (2013) A potent soluble epoxide hydrolase inhibitor, t-AUCB, acts through PPARgamma to modulate the function of endothelial progenitor cells from patients with acute myocardial infarction. Int J Cardiol 167: 1298-1304

162. Shen L, Peng H, Peng R, Fan Q, Zhao S, et al. (2015) Inhibition of soluble epoxide hydrolase in mice promotes reverse cholesterol transport and regression of atherosclerosis. Atherosclerosis 239: 557-565.

163. Christen F, Desrosiers V, Dupont-Cyr BA, Vandenberg GW, Le Francois NR, et al. (2018) Thermal tolerance and thermal sensitivity of heart mitochondria: Mitochondrial integrity and ROS production. Free Radic Biol Med 116: 11-18.

164. Rowe GC, Jiang A, Arany Z (2010) PGC-1 coactivators in cardiac development and disease. Circ Res 107: 825-838.

165. Rodgers JT, Lerin C, Haas W, Gygi SP, Spiegelman BM, et al. (2005) Nutrient control of glucose homeostasis through a complex of PGC-1alpha and SIRT1. Nature 434: 113-118.

166. Kim E, Choi Y, Jang J, Park T (2013) Carvacrol protects against hepatic steatosis in mice fed a high-fat diet by enhancing SIRT1-AMPK signaling. Evid Based Complement Alternat Med 2013: 290104.

167.Patti ME, Butte AJ, Crunkhorn S, Cusi K, Berria R, et al. ( 2003) Coordinated reduction of genes of oxidative metabolism in humans with insulin resistance and diabetes: Potential role of PGC1 and NRF1. Proc Natl Acad Sci USA 100: 8466-8471.

168. Austin S, St-Pierre J (2012) PGC1alpha and mitochondrial metabolismemerging concepts and relevance in ageing and neurodegenerative disorders. J Cell Sci 125: 4963-4971.

169. Schulz E, Dopheide J, Schuhmacher S, Thomas SR, Chen K, et al. (2008) Suppression of the JNK pathway by induction of a metabolic stress response prevents vascular injury and dysfunction. Circulation 118: 1347-1357.

170. Hu CM, Chen YH, Chiang MT, Chau LY (2004) Heme oxygenase-1 inhibits angiotensin II-induced cardiac hypertrophy in vitro and in vivo. Circulation 110: 309-316.

171. Kong X, Wang R, Xue Y, Liu X, Zhang H, et al. (2010) Sirtuin 3, a new target of PGC-1alpha, plays an important role in the suppression of ROS and mitochondrial biogenesis. PLoS One 5: e11707.

172. Kang C, Li Ji (2012) Role of PGC-1alpha signaling in skeletal muscle health and disease. Ann N Y Acad Sci 1271: 110-117.

173. Stotland A, Gottlieb RA (2015) Mitochondrial quality control: Easy come, easy go. Biochim Biophys Acta 1853: 2802-2811.

174.Lin J, Handschin C, Spiegelman BM (2005) Metabolic control through the PGC-1 family of transcription coactivators. Cell Metab 1: 361-370.

175. Abraham NG, Rezzani R, Rodella L, Kruger A, Taller D, et al. (2004) Overexpression of human heme oxygenase- 1 attenuates endothelial cell sloughing in experimental diabetes. Am J Physiol Heart Circ Physiol 287 H2468-H2477.

176. Abraham NG, Kushida T, McClung J, Weiss M, Quan S, et al. (2003) Heme oxygenase-1 attenuates glucose-mediated cell growth arrest and apoptosis in human microvessel endothelial cells. Circ Res 93: 507-514.
177. Biswas SK, Peixoto EB, Souza DS, de Faria JB (2008) Hypertension increases pro-oxidant generation and decreases antioxidant defense in the kidney in early diabetes. Am J Nephrol 28: 133-142.

178. Cao J, Singh SP, McClung J, Joseph G, Vanella L, et al. (2017) EET intervention on Wnt1, NOV and HO-1 signaling prevents obesity-induced cardiomyopathy in obese mice. Am J Physiol Heart Circ Physiol 313: H368-H380.

179. Vanella L, Kim DH, Asprinio D, Peterson SJ, Barbagallo I, et al. (2010) HO-1 expression increases mesenchymal stem cell-derived osteoblasts but decreases adipocyte lineage. Bone 46: 236-243.

180. Galbraith RA, Kappas A (1991) Regulation of food intake and body weight in rats by the synthetic heme analogue cobalt protoporphyrin. Am J Physiol 261: R1388-R1394.

181. Ndisang JF (2010) Role of heme oxygenase in inflammation, insulin-signalling, diabetes and obesity. Mediators Inflamm 2010: 359732.

182. Dagher Z, Ruderman N, Tornheim K, Ido Y (2001) Acute regulation of fatty acid oxidation and amp-activated protein kinase in human umbilical vein endothelial cells. Circ Res 88: 1276-1282.

183. Peterson SJ, Drummond G, Kim DH, Li M, Kruger AL, et al. (2008) L-4F treatment reduces adiposity, increases adiponectin levels, and improves insulin sensitivity in obese mice. J Lipid Res 49: 1658-1669.

184. Nicolai A, Li M, Kim DH, Peterson SJ, Vanella L, et al. (2009) Heme oxygenase-1 induction remodels adipose tissue and improves insulin sensitivity in obesityinduced diabetic rats. Hypertension 53: 508-515.

185. Cao J, Peterson SJ, Sodhi K, Vanella L, Barbagallo I, et al. (2013) Heme oxygenase gene targeting to adipocytes attenuates adiposity and vascular dysfunction in mice fed a high-fat diet. Hypertension 60: 467-475.

186. Roche C, Besnier M, Cassel R, Harouki N, Coquerel D, et al. (2015) Soluble epoxide hydrolase inhibition improves coronary endothelial function and prevents the development of cardiac alterations in obese insulin-resistant mice. Am J Physiol Heart Circ Physiol 308: H1020-H1029.

187. Canto C, Auwerx J (2009) PGC-1alpha SIRT1 and AMPK an energy sensing network that controls energy expenditure. Curr Opin Lipidol 20: 98-105.

188. Chau MD, Gao J, Yang Q, Wu Z (2010) Fibroblast growth factor 21 regulates energy metabolism by activating the AMPK-SIRT1-PGC-1alpha pathway. Proc Natl Acad Sci USA 107: 12553-12558.

189. Vanella L, Sodhi K, Kim DH, Puri N, Maheshwari M, et al. (2013) Increased heme-oxygenase 1 expression decreases adipocyte differentiation and lipid accumulation in mesenchymal stem cells via upregulation of the canonical Wnt signaling cascade. Stem Cell Res Ther 4: 28 .

190.Zhan Y, Kim S, Izumi Y, Izumiya Y, Nakao T, et al. (2003) Role of JNK p38 and ERK in platelet-derived growth factor-induced vascular proliferation migration and gene expression. Arterioscler Thromb Vasc Biol 23: 795-801.

191. Lowe CE, O'Rahilly S, Rochford JJ (2011) Adipogenesis at a glance. J Cell Sci 124: 2681-2686

192. Konrad FM, Braun S, Ngamsri KC, Vollmer I, Reutershan J (2014) Heme oxygenase-1 attenuates acute pulmonary inflammation by decreasing the release of segmented neutrophils from the bone marrow. Am J Physiol Lung Cell Mol Physiol 307: L707-L717.

193. Turkseven S, Kruger A, Mingone CJ, Kaminski P, Inaba M, et al. (2005) Antioxidant mechanism of heme oxygenase-1 involves an increase in superoxide dismutase and catalase in experimental diabetes. Am J Physio Heart Circ Physiol 289: H701-H707.

194. Spiegelman BM (2007) Transcriptional control of energy homeostasis through the PGC1 coactivators. Novartis Found Symp 286: 3-6.

195.Palmieri L, Alberio S, Pisano I, Lodi T, Meznaric-Petrusa M, et al. (2005) Complete loss-of-function of the heart/muscle-specific adenine nucleotide translocator is associated with mitochondrial myopathy and cardiomyopathy. Hum Mol Genet 14: 3079-3088.

196. Arany Z, Wagner BK, Ma Y, Chinsomboon J, Laznik D, et al. (2008) Gene expression-based screening identifies microtubule inhibitors as inducers of PGC-1alpha and oxidative phosphorylation. Proc Natl Acad Sci USA105: 4721-4726.

197. Lehman JJ, Barger PM, Kovacs A, Saffitz JE, Medeiros DM (200) Peroxisome proliferator-activated receptor gamma coactivator-1 promotes cardiac mitochondrial biogenesis. J Clin Invest 106: 847-856. 
Citation: Liu L, Huang X, Gao J, Guo Y, Di Y, et al. (2018) EET Intervention on HO-1 Prevent Obesity Derived Cardiovascular Diseases. J Biomol Res Ther 7: 163. doi:10.4172/2167-7956.1000163

198. Aharoni-Simon M, Hann-Obercyger M, Pen S, Madar Z, (2017) Fatty liver is associated with impaired activity of PPARgamma-coactivator 1alpha (PGC1alpha) and mitochondrial biogenesis in mice. Lab Invest 91: 1018-1028.

199. Arany Z, Foo SY, Ma Y, Ruas JL, Bommi-Reddy A, et al. (2008) HIFindependent regulation of VEGF and angiogenesis by the transcriptional coactivator PGC-1alpha. Nature 451: 1008-1012.

200. Arany Z, He H, Lin J, Hoyer K, Handschin C, et al. (2005) Transcriptional coactivator PGC-1 alpha controls the energy state and contractile function of cardiac muscle. Cell Metab 1: 259-271.

201.Barger PM, Brandt JM, Leone TC, Weinheimer CJ, Kelly DP, et al. (2000) Deactivation of peroxisome proliferator-activated receptor-alpha during cardiac hypertrophic growth. J Clin Invest 105: 1723-1730.

202. Bostrom P, Wu J, Jedrychowski MP, Korde A, Ye L, et al. (2012) A PGC1alpha-dependent myokine that drives brown-fat-like development of white fat and thermogenesis. Nature 481: 463-468.

203. Lehman JJ, Boudina S, Banke NH, Sambandam N, Han X, et al. (2008) The transcriptional coactivator PGC-1alpha is essential for maximal and efficient cardiac mitochondrial fatty acid oxidation and lipid homeostasis. Am J Physiol Heart Circ Physiol 295: H185-H196.

204. Arany Z, Novikov M, Chin S, Ma Y, Rosenzweig A, et al. (2006) Transverse aortic constriction leads to accelerated heart failure in mice lacking PPARgamma coactivator 1alpha. Proc Natl Acad Sci USA 103: 10086-10091.

205. Ali F, Ali NS, Bauer A, Boyle JJ, Hamdulay SS, et al. (2010) PPARdelta and PGC1alpha act cooperatively to induce haem oxygenase-1 and enhance vascular endothelial cell resistance to stress. Cardiovasc Res 85: 701-710.

206. Wu HF, Chen YJ, Wu SZ, Lee CW, Chen IT, et al. (2017) Soluble epoxide hydrolase inhibitor and 14,15-epoxyeicosatrienoic acid-facilitated long-term potentiation through cAMP and CaMKII in the hippocampus. Neural Plast 3467805 .

207.Imig JD (2006) Cardiovascular therapeutic aspects of soluble epoxide hydrolase inhibitors. Cardiovasc Drug Rev 24: 169-188.

208. Romashko M, Schragenheim J, Abraham NG, McClung JA (2016) Epoxyeicosatrienoic acid as therapy for diabetic and ischemic cardiomyopathy. Trends Pharmacol Sci 37: 945-962.

209. Sodhi K, Puri N, Inoue K, Falck JR, Schwartzman ML, et al. (2012) EET agonist prevents adiposity and vascular dysfunction in rats fed a high fat diet via a decrease in Bach 1 and an increase in HO-1 levels. Prostaglandins Other Lipid Mediat 98: 133-142.

210. Gauthier KM, Yang W, Gross GJ, Campbell WB (2007) Roles of epoxyeicosatrienoic acids in vascular regulation and cardiac preconditioning. J Cardiovasc Pharmacol 50: 601-608.
211. Huang $\mathrm{H}$, Weng J, Wang MH (2016) EETs/sEH in diabetes and obesity-induced cardiovascular diseases. Prostaglandins Other Lipid Mediat 125: 80-89.

212.Wagner KM, McReynolds CB, Schmidt WK, Hammock BD (2017) Soluble epoxide hydrolase as a therapeutic target for pain, inflammatory and neurodegenerative diseases. Pharmacol Ther 180: 62-76.

213. Kaklamani VG, Wisinski KB, Sadim M, Gulden C, Do A, et al. (2008) Variants of the adiponectin (ADIPOQ) and adiponectin receptor 1 (ADIPOR1) genes and colorectal cancer risk. JAMA 300: 1523-1531.

214. Simpkins AN, Rudic RD, Schreihofer DA, Roy S, Manhiani M, et al. (2009) Soluble epoxide inhibition is protective against cerebral ischemia via vascular and neural protection. Am J Pathol 174: 2086-2095

215. Neckar J, Kopkan L, Huskova Z, Kolar F, Papousek F, et al. (2012) Inhibition of soluble epoxide hydrolase by cis-4-[4-(3-adamantan-1-ylureido)cyclohexyloxy]benzoic acid exhibits antihypertensive and cardioprotective actions in transgenic rats with angiotensin II-dependent hypertension. Clin Sci (Lond) 122: 513-525

216.Zhu D, Effros RM, Harder DR, Roman RJ, Jacobs ER, et al. (1998) Tissue sources of cytochrome P450 4A and 20-HETE synthesis in rabbit lungs. Am J Respir Cell Mol Biol 19:121-128

217. Sato K, Emi M, Ezura Y, Fujita Y, Takada D, et al. (2004) Soluble epoxide hydrolase variant (Glu287Arg) modifies plasma total cholesterol and triglyceride phenotype in familial hypercholesterolemia: Intrafamilial association study in an eight-generation hyperlipidemic kindred. J Hum Genet 49: 29-34.

218. Bettaieb A, Nagata N, AbouBechara D, Chahed S, Morisseau C, et al. (2004 Soluble epoxide hydrolase deficiency or inhibition attenuates diet-induced endoplasmic reticulum stress in liver and adipose tissue. J Biol Chem 288: 14189-14199.

219. Imig JD, Hammock BD (2009) Soluble epoxide hydrolase as a therapeutic target for cardiovascular diseases. Nat Rev Drug Discov 8: 794-805.

220. Marino JP Jr. (2009) Soluble epoxide hydrolase, a target with multiple opportunities for cardiovascular drug discovery. Curr Top Med Chem 9: 452463.

221.Schuck RN, Theken KN, Edin ML, Caughey M, Bass A, et al. (2013) Cytochrome P450-derived eicosanoids and vascular dysfunction in coronary artery disease patients. Atherosclerosis 227: 442-448.

222. Podolin PL, Bolognese BJ, Foley JF, Long E III, Peck B, et al. (2013) In vitro and in vivo characterization of a novel soluble epoxide hydrolase inhibitor. Prostaglandins Other Lipid Mediat 104-105: 25-31.

223. Lazaar AL, Yang L, Boardley RL, Goyal NS, Robertson J, et al. (2015) Pharmacokinetics, pharmacodynamics and adverse event profile of GSK2256294, a novel soluble epoxide hydrolase inhibitor. Br J Clin Pharmacol 81: $971-979$. 